\title{
Möhöjuuren esiintyminen suomalaisilla rypsi- ja rapsiviljelmillä
}

Marika Rastas, Satu Latvala ja Asko Hannukkala

Maa- ja elintarviketalouden tutkimuskeskus, Kasvintuotannon tutkimus, Planta, 31600 Jokioinen, etunimi.sukunimi@mtt.fi

\section{Tiivistelmä}

Möhöjuuri on Plasmodiophora brassicae-eliön aiheuttama maalevintäinen kasvitauti. Suomessa möhöjuuri on tunnettu kaalilajien ja ristikukkaisten juuresten vakavana tautina jo 1800-luvun lopulta asti. 1970-luvulla alkanut rypsin- ja rapsinviljelyn suosion kasvu on nostanut niiden viljelypinta-alan huippuvuosina yli 100000 hehtaariin. Tämä on moninkertaistanut möhöjuurituhoille alttiiden kasvien viljelyalan.

Tässä tutkimuksessa kartoitettiin möhöjuuren levinneisyyttä ja merkitystä suomalaisilla rypsi- ja rapsiviljelmillä. Peltokartoitukset tehtiin vuosina 1984-1989 ja 2007-2009 yhteensä 850 peltolohkolla. Kartoituksen mukaan möhöjuurta esiintyy yleisesti rypsin viljelyalueella Etelä-Suomesta Pohjanmaalle, noin kolmanneksella tutkituista peltolohkoista. Rypsin ja rapsin vuosittaisen viljelyalan kasvun ja möhöjuuren esiintymisen välillä havaittiin yhteys, sillä runsain esiintyminen seurasi ajanjaksoja, jolloin rypsin ja rapsin viljelyala lisääntyi. Kartoituksen perusteella tärkein taudin yleisyyteen ja vakavuuteen vaikuttanut tekijä oli ristikukkaisten kasvien viljelytiheys: möhöjuurta löydettiin yli puolelta pelloista, joilla oli alle kahden vuoden tauko rypsin viljelyssä. Näillä pelloilla myös sairaiden kasvien osuus oli suurempi. Viljelytiheyden harventuessa möhöjuuren esiintyminen väheni selvästi.

Maan happamuuden tiedetään suosivan möhöjuuren oireiden puhkeamista. Tämän kartoituksen mukaan viljelymaan happamuus lisäsi möhöjuuren ankaruutta, mutta taudin esiintymiseen sillä ei ollut vaikutusta. Pahimmat tautioireet havaittiin peloilla, joiden $\mathrm{pH}$ oli alle 6,7, mutta tautia havaittiin myös neutraaleilta ja emäksisiltä mailta.

Kartoituksen lisäksi tutkittiin myös möhöjuuren säilymistä maassa jatkuvassa rypsinviljelyssä, viljanviljelyssä, monivuotisella nurmella sekä avokesannolla. Möhöjuuren infektiokyky väheni alhaiselle tasolle neljän vuoden ristikukkaisten viljelytauon jälkeen. Välivuosien viljelykasveilla ei ollut merkitystä taudinaiheuttajan häviämisnopeuteen. Vaikka möhöjuuri väheni ristikukkaisten viljelytauon aikana, taudinaiheuttaja pystyttiin eristämään maasta vielä 19 vuoden tauon jälkeenkin. Tämä osoittaa, että taudin täydellinen hävittäminen maasta on hyvin vaikeaa.

Taudin yleisyyden, pitkän säilyvyyden ja vaikean torjunnan takia möhöjuuri on merkittävä uhka rypsin viljelylle. Mikäli viljelykierroista joudutaan tinkimään viljelyalojen kasvaessa, voi se johtaa taudin nopeaan yleistymiseen rypsi- ja rapsiviljelmillä.

Asiasanat: möhöjuuri, Plasmodiophora brassicae, rypsi, rapsi, pH, viljelykierto, säilyminen 


\section{Johdanto}

Viljelyalan merkittävä lisääminen ja satotason nostaminen on edellytys rypsin ja rapsin riittävyydelle elintarvikkeiden, rehujen sekä biodieselin raaka-aineeksi. Viime vuosina öljykasvien merkitys elintarvike- ja rehuteollisuuden raaka-aineena on entisestään korostunut mm. etsittäessä keinoja valkuaisomavaraisuuden lisäämiseksi. Kasvitaudit, erityisesti möhöjuuri, rajoittavat ristikukkaisten kasvien tuotannon laajentamista, sillä ne laskevat satoa ja heikentävät tuotannon tehokkuutta.

Möhöjuuri on merkittävä rypsin ja rapsin kasvitauti, koska se on maalevintäinen, sillä on laaja isäntäkasvivalikoima ja se säilyy pitkään maassa tartutuskykyisenä (Dixon 2009). Taudin torjunta on hankalaa erityisesti peltomittakaavan kasveilla (Donald \& Porter 2009). Taudin aiheuttaa Juurijalkaisiin kuuluva Plasmodiophora brassicae-eliö. Suomessa möhöjuuri on tunnettu kaalilajien ja ristikukkaisten juuresten vakavana tautina jo 1800-luvun lopulta asti (Woronin 1878, Jamalainen 1936). 1970-luvulla alkanut rypsin- ja rapsinviljelyn suosion kasvu on nostanut ristikukkaisten öljykasvien viljelypinta-alan huippuvuosina yli 100000 hehtaariin. Tämä on moninkertaistanut möhöjuurituhoille alttiiden kasvien viljelyalan.

Tutkimuksen tavoitteena oli kartoittaa möhöjuuren tämänhetkinen esiintyminen ristikukkaisten öljykasvien viljelyssä ja verrata sitä 1980-luvun tilanteeseen sekä selvittää taudin esiintymiseen ja vakavuuteen vaikuttavia seikkoja.

\section{Aineisto ja menetelmät}

Rypsi- ja rapsiviljelmien peltokartoitukset toteutettiin yksityisten viljelijöiden pelloilla tärkeimmillä viljelyaluilla Etelä- ja Länsi-Suomessa vuosina1984-1989 ja 2007-2009. Vuosittain tutkittiin 30-181 peltoa, joista jokaisesta kerättiin keskimäärin 24-186 kasvinäytettä. Kasvit kerättiin tasaisin välimatkoin w-muotoiselta, koko pellon kattavalta reitiltä. Kasvien möhöjuurioireet arvioitiin silmämääräisesti käyttäen neliluokkaista asteikkoa Williamsin (1966) mukaan. Möhöjuuren esiintymiseen vaikuttavia tekijöitä analysoitiin vain vuosien 2007-2009 aineistosta.

Säilymiskokeessa luonnollisesti möhöjuuren täysin saastuttamalle pellolle perustettiin vuonna 1991 neljä erilaista viljelylohkoa: jatkuva rypsi, vehnä-kaura-ohra-viljelykierto, monivuotinen nurmi sekä avokesanto. Jokaisesta lohkosta otettiin syyskuussa maanäyte, josta määritettiin möhöjuuren infektiivisyys pyydyskasveilla (alttiin rypsilajikkeen taimet).

\section{Tulokset ja tulosten tarkastelu}

\section{Möhöjuuren esiintyminen rypsi- ja rapsiviljelmillä}

Vuosina 1984-1989 ja 2007-2009 toteutettujen peltokartoitusten mukaan möhöjuurta esiintyy rypsin kaikilla merkittävimmillä viljelyalueella Etelä-Suomesta Pohjanmaalle (kuvio 1.). Pohjanmaalla ei 1980-luvun kartoituksessa havaittu lainkaan möhöjuurta. Uudemmassa kartoituksessa taudin esiintymisessä ei ollut suuria maantieteellisiä eroja, tosin vakavia tautitapauksia ei vieläkään löydetty pohjoisimmilta viljelyalueilta.

Möhöjuurta havaittiin keskimäärin kolmanneksella tutkituista peltolohkoista, vuosittainen vaihtelu oli kuitenkin melko suurta (kuvio 2). Rypsin ja rapsin vuosittaisen viljelyalan kasvun ja möhöjuuren esiintymisen välillä havaittiin yhteys, sillä runsain esiintyminen seurasi ajanjaksoja, jolloin rypsin ja rapsin viljelyala lisääntyi. Tämän kartoituksen perusteella möhöjuurta esiintyy Suomessa rypsi- ja rapsiviljelmillä puolet vähemmän kuin ristikukkaisilla vihanneksilla, joiden möhöjuuritilanteen Linnasalmi \& Toiviainen (1991) kartoittivat 1970-luvulla. Möhöjuuren yleisyys vihanneksilla johtunee vihannesviljelyn pidemmästä historiasta Suomessa sekä intensiivisemmästä viljelystä. Ruotsissa, missä rypsiä ja rapsia on viljelty 1940-luvulta asti, möhöjuuri on yleisempi kuin Suomessa. Möhöjuurta esiintyy Ruotsissa yli puolella rypsi- ja rapsipelloista, Örebron alueella jopa $78 \%$ pelloista on möhöjuuren saastuttamia (Engqvist 1994, Wallenhammar 1996). Voidaan siis päätellä, että pitkään jatkunut ja intensiivinen viljely lisää möhöjuuren esiintymistä. 


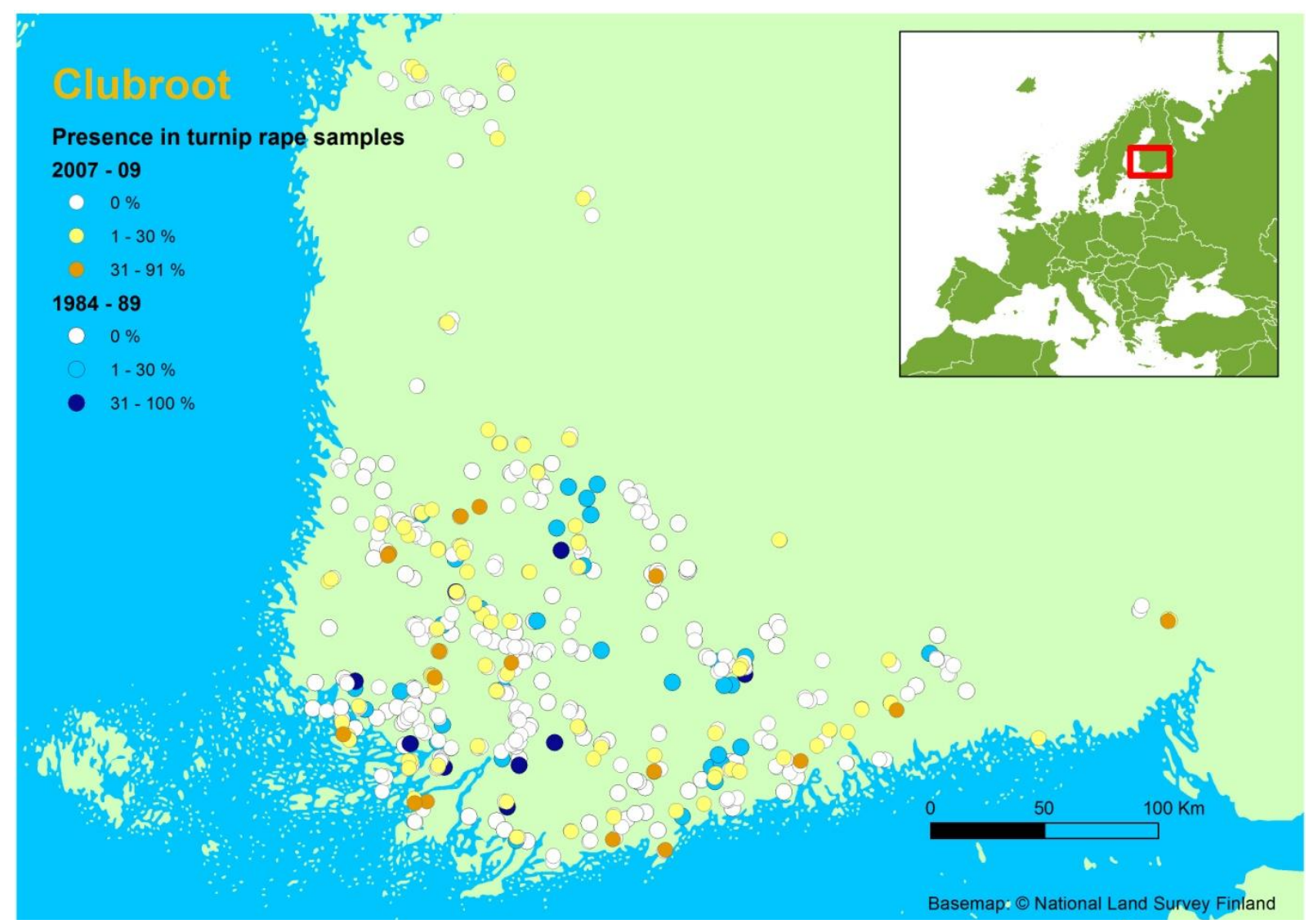

Kuvio 1. Möhöjuuren esiintyminen rypsi- ja rapsipelloilla 2000-luvun ja 1980-luvun kartoituksissa. Tällä hetkellä möhöjuurta esiintyy yleisesti koko rypsin ja rapsin viljelyalueella. Möhöjuuren esiintymisessä ei havaittu merkittäviä maantieteellisiä eroja, paitsi Pohjamaalla ei 1980-luvulla havaittu möhöjuurta ja myöhemminkin siellä esiintyi vain lieviä tautitapauksia.

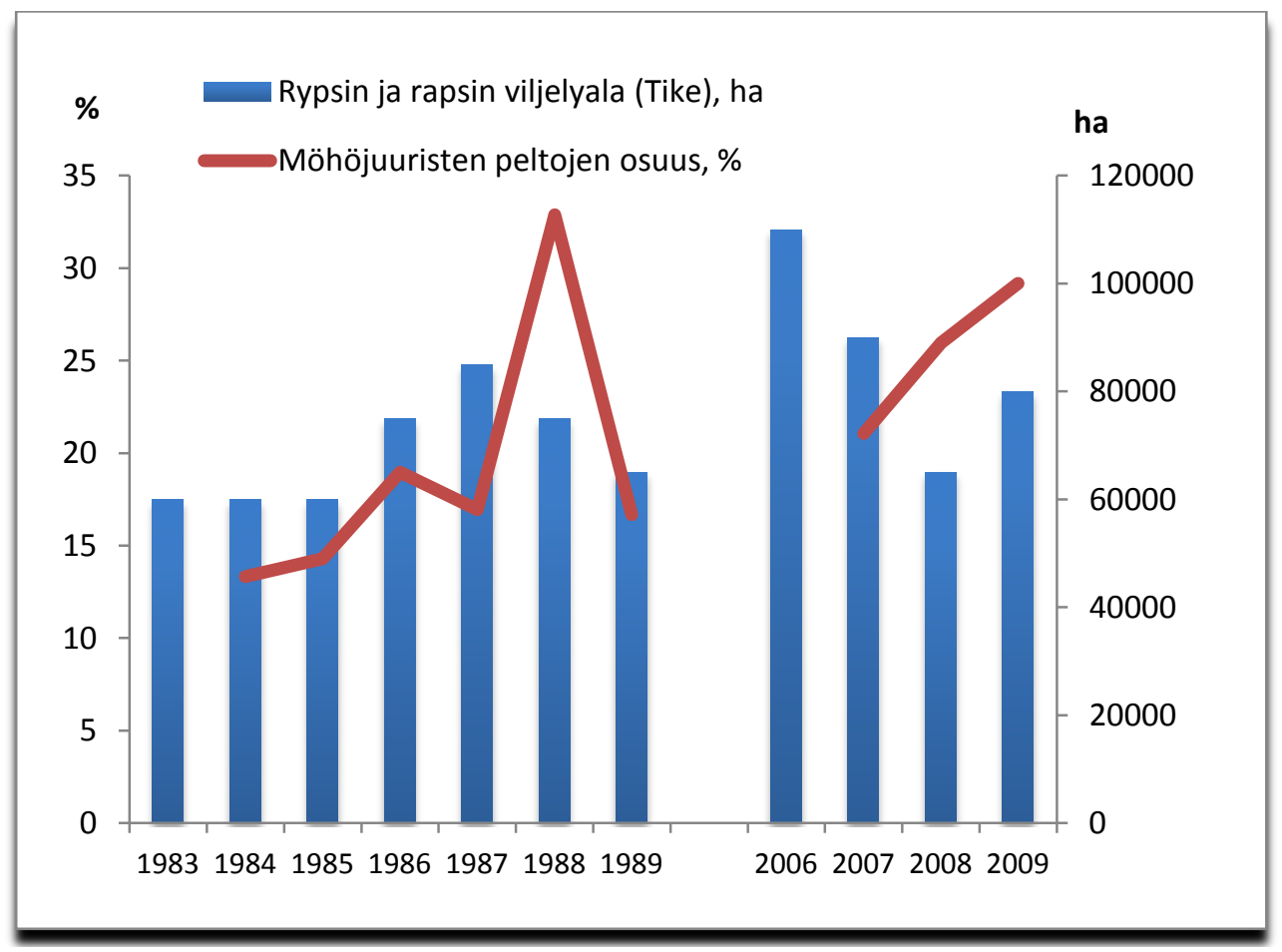

Kuvio 2. Rypsin ja rapsin viljelyala sekä möhöjuuristen peltojen osuus kartoituksessa. Möhöjuuren esiintymisessä oli suurta vuosittaista vaihtelua. Taudin esiintyminen yleistyi viljelyalojen kasvun jälkeen. 


\section{Viljelykierto}

Kartoituksessa havaitusta laajasta esiintymisestä huolimatta, valtaosalla möhöjuuren saastuttamista lohkoista sairastuneiden kasvien osuus oli pieni ja oireet lieviä. Kartoituksessa havaittiin selvä yhteys möhöjuuren vakavuuden ja ristikukkaisten viljelytiheyden välillä (kuvio 3). Hyvin toteutetulla viljelykierrolla oli merkittävä osuus taudin vähäiseen tuhoisuuteen, sillä vain kolmasosalla lohkoista ristikukkaisten kasvien viljelyväli oli neljä vuotta tai vähemmän. Möhöjuurta havaittiin yli puolelta pelloista, joilla ristikukkaisten viljelyväli oli kaksi vuotta tai vähemmän. Kun ristikukkaisten kasvien viljelyväli oli yli viisi vuotta, möhöjuurta löytyi vain $20 \%$ pelloista. Ristikukkaisten tiheä viljely lisäsi merkittävästi myös sairaiden kasvien osuutta lohkoilla. Viljelytiheydellä oli myös merkitsevä vaikutus vakavien oireiden osuuteen (data ei esillä).

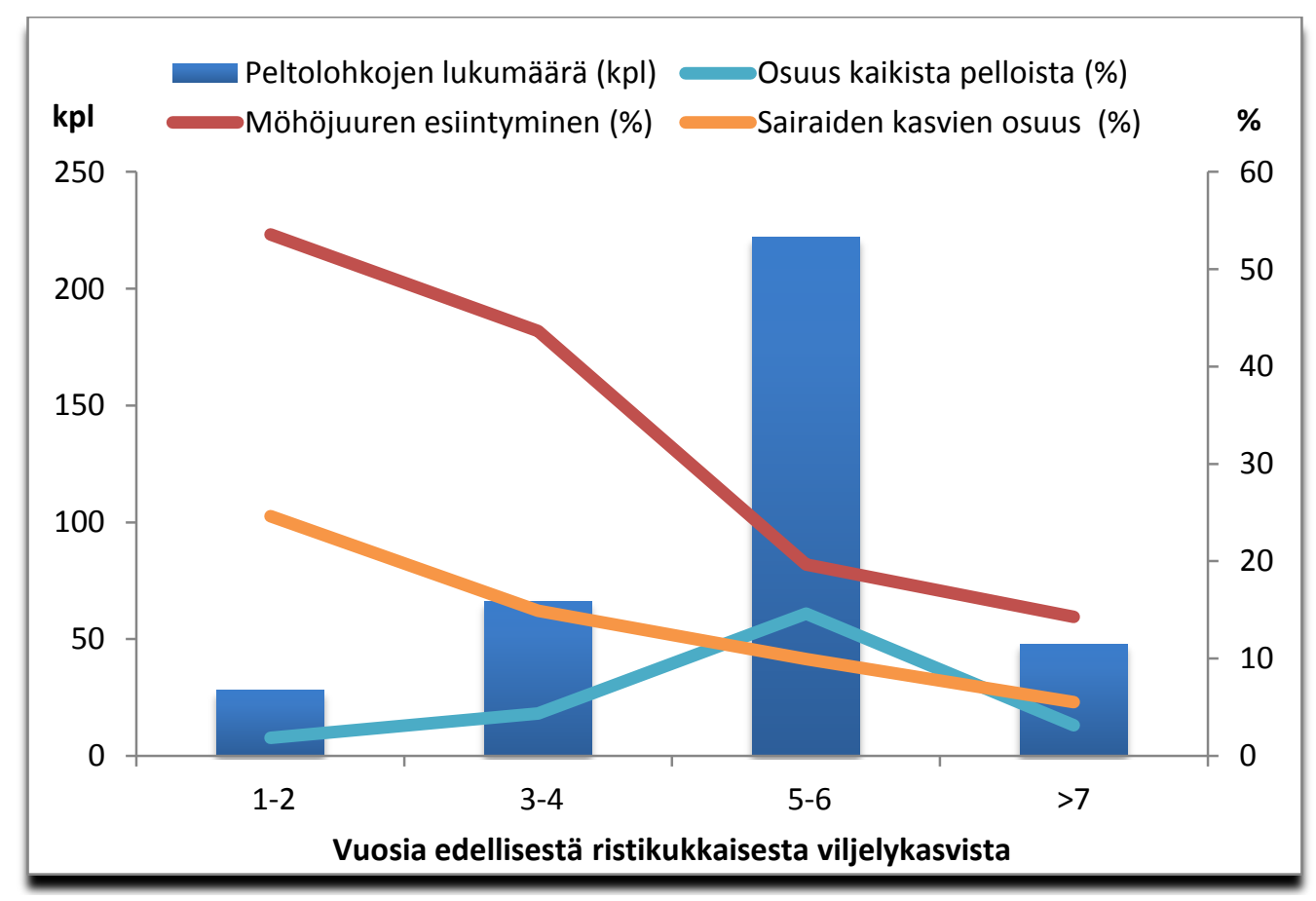

Kuvio 3. Ristikukkaisten kasvien viljelytaajuus ja möhöjuuren esiintyminen. Möhöjuuren esiintyminen sekä sairaiden kasvien osuus lohkolla vähenee selvästi kun aika edellisestä ristikukkaisesta viljelykasvista pitenee.

\section{Maan happamuus}

Tehdyn kartoituksen perusteella viljelymaan happamuus ei vaikuttanut merkittävästi möhöjuuren esiintymiseen peltolohkoilla. Lohkot jaettiin kahteen yhtä suureen ryhmään, $\mathrm{pH}<6,5 \mathrm{ja} \mathrm{pH}>6,5$. Ryhmien välillä oli vain vähäinen ero, sillä matalammassa $\mathrm{pH}$ :ssa möhöjuurta esiintyi $28 \%$ :lla ja korkeammassa $23 \%$ :lla lohkoista. Möhöjuurta löydettiin pelloilta joiden pH oli 5-7,6 eli se esiintyi hyvin laajalla pH-alueella. Vakavia tautitapauksia (yli $10 \%$ kasveista sairaita) havaittiin kuitenkin vain peloilla, joiden pH oli alle 6,7. Myös Ruotsissa ja Kanadassa tehdyissä peltokartoituksissa möhöjuurta on havaittu neutraaleissa peltomaissa (Wallenhammar 1996, Strelkov et al. 2007). Vaikka pH ei vaikuttanut taudin esiintymiseen, matala $\mathrm{pH}$ lisäsi selvästi sairaiden kasvien sekä vakavien ja keskimääräisten oireiden osuutta (kuvio 4). Maan happamuuden tiedetään suosivan möhöjuuren oireiden puhkeamista ja kalkituksen on osoitettu heikentävän möhöjuuren oireiden kehittymistä (Webster \& Dixon 1991, Murakami et al. 2002). Koska möhöjuuri voi kuitenkin esiintyä laajalla pH-alueella, peltomittakaavassa kalkituksen teho möhöjuuren torjunnassa on kuitenkin rajallinen. 


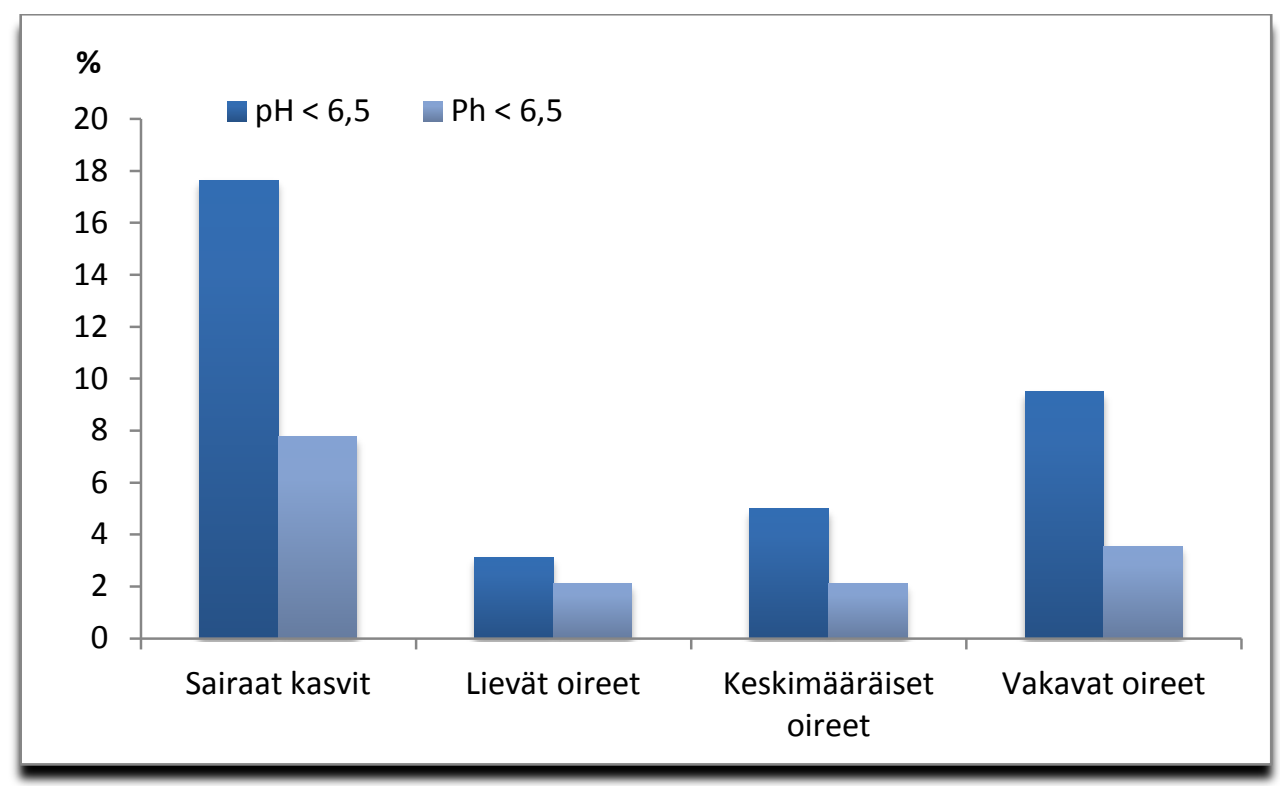

Kuvio 4. Happamuuden vaikutus sairaiden kasvien osuuteen lohkon kasveista sekä oireluokkien osuuksiin. Kaikissa ryhmissä, paitsi lievien oireiden osuudessa, on happamuusluokkien välillä tilastollisesti merkitsevää ero Tukeyn testin mukaan $(\mathrm{p}<0,05)$.

\section{Möhöjuuren säilyminen maassa}

Jatkuvassa rypsinviljelyssä infektoituneiden pyydyskasvien väärä vaihteli vuosittain, mutta yli puolella pyydyskasveista oli joka vuosi möhöjuuren oireita (kuvio 5). Möhöjuuren havaittiin vähenevän selvästi ensimmäisten neljän vuoden jälkeen nurmella, kesannolla sekä viljalla eikä viljelykasvilla ollut merkittävää vaikutusta häviämisnopeuteen. Kymmenen vuoden jälkeen tautia havaittiin näiltä lohkoilta vain hyvin pieniä pitoisuuksia, mutta vielä 19 vuoden jälkeenkin möhöjuuri voitiin eristää pyydyskasveilla peltomaasta. Wallenhammar (1996) on todennut möhöjuuren häviävän maasta 17 vuodessa ilman isäntäkasveja, mutta maan ominaisuudet voivat vaikuttaa häviämisnopeuteen. Tulos osoittaa möhöjuuren hyvin vaikeaksi hävittää kerran saastuneesta peltomaasta.

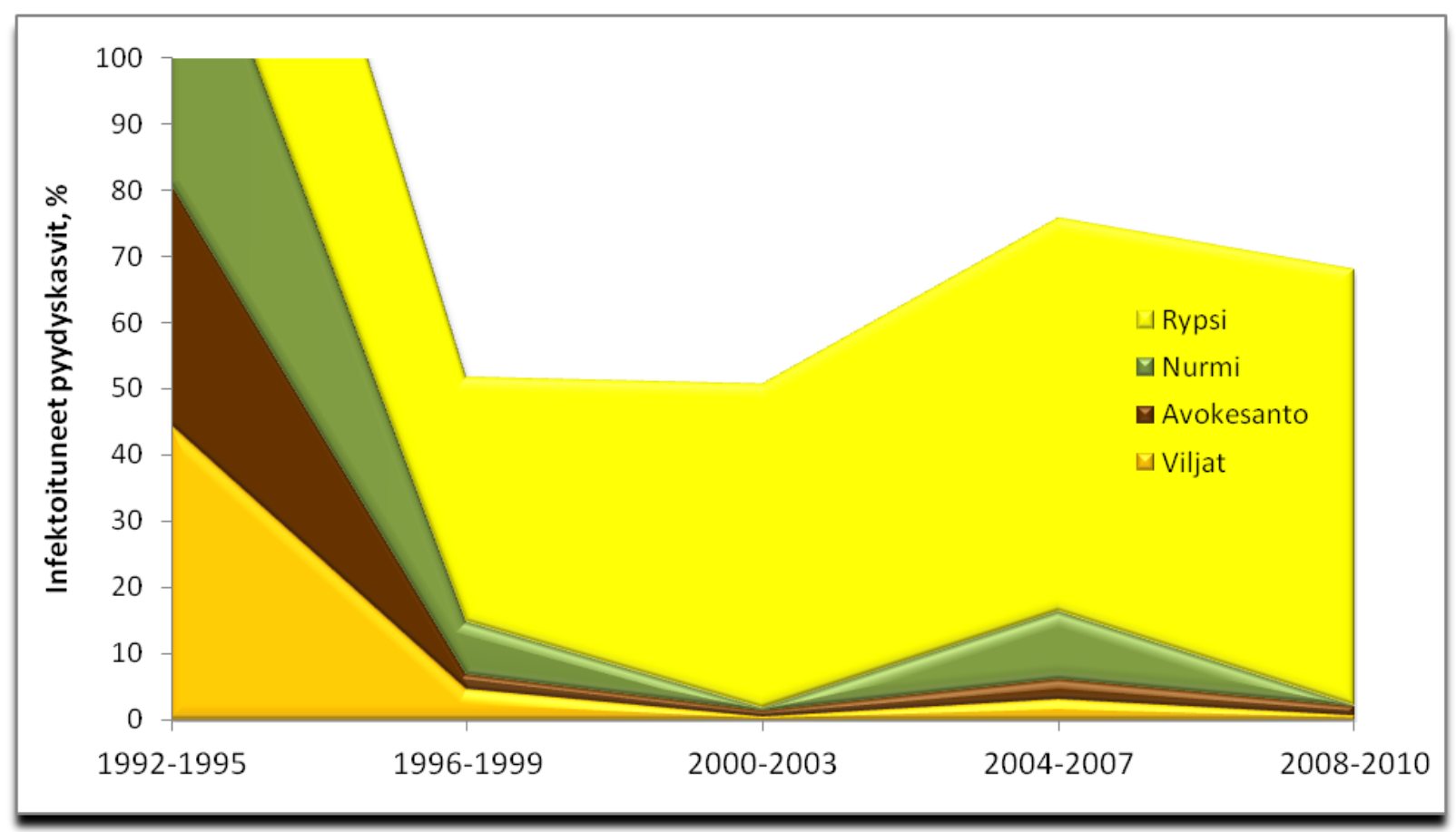

Kuvio 5. Infektoituneet pyydyskasvit (neljän vuoden keskiarvot) möhöjuuren säilymiskokeessa. Möhöjuuren infektiivisyys vähenee selvästi jo ensimmäisen kolmen vuoden jakson jälkeen, kun lohkolla ei ole rypsiä. 


\section{Johtopäätökset}

Hyvin toteutettujen viljelykiertojen ansiosta möhöjuuri on tällä hetkellä pääosin hallinnassa ja se aiheuttaa vain harvassa tapauksessa merkittäviä tuhoja. Tautia havaitaan kuitenkin yleisesti koko öljykasvien viljelyalueella, joten sen aiheuttamat tuhot voivat lisääntyä mikäli tautiin ei kiinnitetä tarpeeksi huomiota. Taudin täydellinen hävittäminen maasta on erittäin vaikeaa ja torjuntakeinojen, kuten kalkituksen, teho on rajallinen peltomittakaavan viljelyssä. Tärkein keino taudin hallinnassa on riittävä viljelykierto. Mikäli viljelykierrosta joudutaan viljelyalojen kasvaessa tinkimään, lisääntyy riski möhöjuuren yleistymisestä ja tuhojen pahenemisesta.

\section{Kirjallisuus}

Dixon, G.R. 2009. The occurrence and economic impact of Plasmodiophora brassicae and clubroot disease. Journal of Plant Growth Regulation 28: 194-202.

Donald, C. \& Porter, I. 2009. Integrated control of clubroot. Journal of Plant Growth Regulation 28: 289-303.

Engqvist, L.G. 1994. Distribution of clubroot (Plasmodiophora brassicae Wor) in Sweden and the effect of infection on oil content of oilseed rape (Brassica napus L.). Sveriges Utsadesforenings Tidskrift 104: 82-86.

Jamalainen, E.A. 1936. Tutkimuksia möhöjuuresta (Plasmodiophora brassicae Wor.). Valtion maatalouskoetoiminnan julkaisuja 85: 5-36. Referat: Untersuchungen über die Kohlhernie (Plasmodiophora brassicae Wor.). Die Staatliche Landwirtschaftliche Versuchstätigkeit Veröfföffentlichung 85: 32-36

Linnasalmi, A. \& Toiviainen, A. 1991. Occurrence of clubroot and Plasmodiophora brassicae Wor. races in Finland. Journal of Agricultural Science in Finland 63: 415-434.

Murakami, H., Tsushima, S., Kuroyanagi, Y. \& Shishido, Y. 2002. Reduction of resting spore density of Plasmodiophora brassicae and clubroot disease severity by liming. Soil Science and Plant Nutrition, 48 (5) Pp.685-691, 2002.

Wallenhammar, A-C. 1996. Prevalence of Plasmodiophora brassicae in a spring oilseed rape growing area in central Sweden and factors influencing soil infestation levels. Plant Pathology 45: 710-719.

Webster, M.A. \& Dixon, G.R. 1991. Calcium, Ph and Inoculum Concentration Influencing Colonization by Plasmodiophora-Brassicae. Mycological Research 95: 64-73.

Williams, P.H. 1966. A system for determination of races of Plasmodiophora brassicae that infect cabbage and rutabaga. Phytopathology 56: 624-\&.

Woronin, M. 1878. Plasmodiophora brassicae, Urheber der Kohlpflanzen - Hernie. Jahrbuch für Wissenschaftlche Botanik 11: 548-574 